\title{
Numerical Simulation for Remediation Planning for 1,4-Dioxane-Contaminated Groundwater at Kuwana Illegal Dumping Site in Japan Based on the Concept of Verified Follow Up
}

\author{
Ramrav Hem, Toru Furuichi, Kazuei Ishii, Yu-Chi Weng \\ Laboratory of Sound Material-Cycle Systems Planning, Graduate School of Engineering, \\ Hokkaido University, Sapporo, Japan \\ Email: hemramrav@gmail.com
}

Received April 29, 2013; revised May 30, 2013; accepted June 20, 2013

Copyright (C) 2013 Ramrav Hem et al. This is an open access article distributed under the Creative Commons Attribution License, which permits unrestricted use, distribution, and reproduction in any medium, provided the original work is properly cited.

\begin{abstract}
At Kuwana illegal dumping site in Japan, where hazardous waste was illegally dumped, groundwater was severely contaminated by Volatile Organic Compounds (VOCs). Groundwater was already remedied by conducting Pump-and-Treat (P\&T) after containment of all the waste by vertical slurry walls from 2002 to 2007. However, 1,4-dioxane was detected in both waste and groundwater outside of slurry walls after it was newly added into Japan environmental standards in late 2009, which suggested that the walls did not contain 1,4-dioxane completely. Our previous study developed a model to predict the 1,4-dioxane distribution in groundwater after the previous remediation at the site. In this study, numerical simulation was applied for remediation planning at the site based on the concept of Verified Follow Up (VF-UP) that had been proposed as a new approach to complete remediation effectively with consideration of future risks. The amount of waste to be removed and pumping plans were discussed by numerical simulation to achieve the remedial objective in which 1,4-dioxane in groundwater outside of walls is remedied within 10 years and 1,4-dioxane spreading throughout the walls is prevented in the case where a portion of waste is remained. Firstly, the amount of waste to be removed considering pumping plans for P\&T was determined by scenario analysis. As a result, at least two-third of waste should be removed by combining with P\&T. However, if the waste is remained, future risks of 1,4-dioxane spreading through the slurry walls may occur. Our simulation suggested that groundwater within the remaining waste must be pumped up at least $20 \mathrm{~m}^{3} / \mathrm{d}$ for containment of 1,4-dioxane within the remaining waste. In conclusion, our numerical simulation determined the amount of waste to be removed and the pumping plans for P\&T to achieve the remedial objective effectively considering future risks based on the concept of VF-UP.
\end{abstract}

Keywords: Remediation Planning; Numerical Simulation; Verified Follow Up; Pump-and-Treat;

1,4-Dioxane-Contaminated Groundwater; Illegal Dumping Site

\section{Introduction}

In Japan, after the rapid economic growth in mid-20th century, environmental pollution has become a serious issue caused by industrial activities [1]. The problem of illegal dumping of industrial waste has been prolonged through decades because of, e.g., lack of landfills, high cost for waste management, and many mountainous areas where illegal dumping can be easily carried out $[2,3]$. The number of illegal dumping increased over 1000 cases from 1998 to 2001 [4]. Recently, the solution of illegal dumping has become a major importance, since illegal dumping threatens the society's safety and security [5-8].
The restoration and recovery of illegal dumping sites to meet the conditions regulated by law or environmental standards poses a variety of problems including not only the impacts on the surrounding environments but also major economic losses because it requires sophisticated technologies and long remediation period $[4,5,8]$.

Kuwana illegal dumping site is one of those cases where the contaminated waste was illegally dumped between 1995 and 1996. Since then, groundwater had been contaminated by Volatile Organic Compounds (VOCs). From 2002 to 2007, remedial measures, e.g., containment all the waste by constructing vertical slurry walls and 
treatment by conducting Pump-and-Treat (P\&T) were carried out to treat VOCs completely. Groundwater quality has been monitored after completion of VOCs remediation for future risks. In late 2009, after 1,4-dioxane was added into Japan environmental standards with the limit concentration of $0.05 \mathrm{mg} / \mathrm{L}, 1,4$-dioxane with high concentration was detected in groundwater at Kuwana site inside and outside of the walls [9]. Similarly, studies had reported that leachate at several landfill sites in Japan contains significant levels of 1,4-dioxane [10-12]. The US EPA and International Agency for Research on Cancer classified 1,4-dioxane as Group 2B (possibly carcinogenic to human being) [13]. Therefore, remediation plan should be developed and implemented immediately to treat 1,4-dioxane in groundwater at the site and to prevent 1,4-dioxane from spreading into the surrounding environment.

Although previous measures have been applied for VOCs remediation at Kuwana site, they could not be effective to complete 1,4-dioxane remediation because 1,4dioxane is expected to migrate in groundwater without biodegradation and adsorption to soil according to its unique properties [14-18]. Consequently, 1,4-dioxane might be more difficult to be contained by groundwater level control without waste removal. Regarding this problem, this study focused on developing remediation plan by using numerical simulation based on the concept of Verified Follow Up (VF-UP). VF-UP is a new approach developed by [19] for remedial planning for groundwater-contaminated sites, considering future expected and/ or unexpected uncertain events to complete remediation effectively. Several studies have been conducted by applying the numerical simulation for groundwater contaminated site remediation focusing on mostly the par- ticular elemental technique e.g., optimization of pumping rates, pumping locations, remediation time and costs [14,20-26]. However, our study focused on the application of numerical simulation for the whole remediation plan considering the element techniques. The element techniques can be flexible to be changed based on the actual conditions of remediation at the site. Moreover, since VF-UP was newly developed, there is no study that proves its application to the real contaminated site, especially in remediation planning using numerical simulation.

Our previous study [27] developed a model to predict the 1,4-dioxane distribution in groundwater to represent the groundwater flow and 1,4-dioxane distribution conditions after the previous remediation at the site. The developed model will be modified regarding the condition in remediation planning considering the same parameters and setting. The remedial objective in this study is to treat 1,4-dioxane in groundwater outside of slurry walls within 10 years which is limited to national subsidy and to prevent 1,4-dioxane from spreading throughout the walls to the surrounding environment. In this study, numerical simulation was applied to analyze the amount of waste to be removed and the pumping plans for treating 1,4-dioxane-contaminated groundwater at Kuwana illegal dumping site based on the concept of VF-UP.

\section{Site Description and Previous Study}

Kuwana illegal dumping site is located in Kuwana city, Mie Prefecture, Japan (see Figures 1(a) and (b)). This site was originally designed and operated as an inert-type landfill. Due to the poor control, hazardous wastes, e.g., ash, sludge, and waste oil including hazardous materials

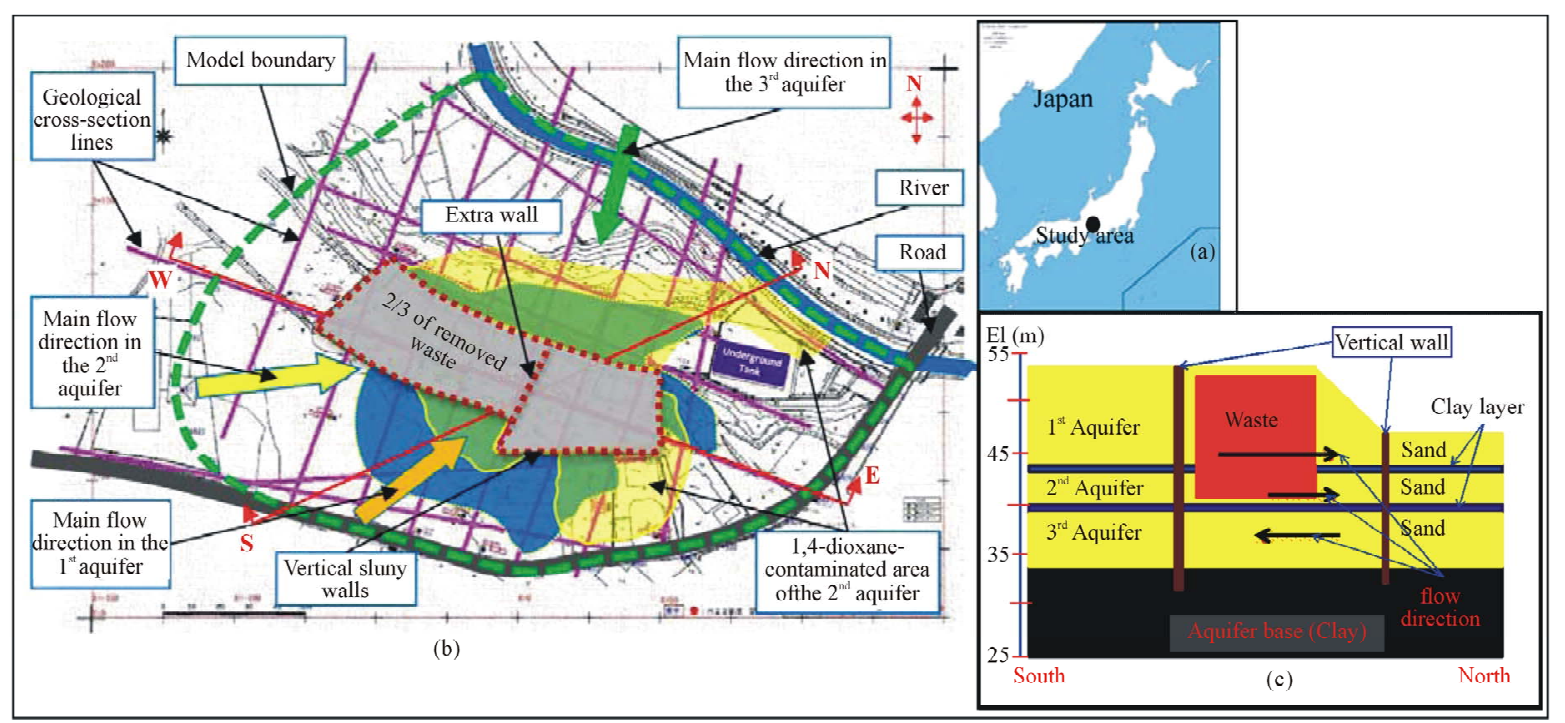

Figure 1. Location map (a), base map (b), and simplified south-north section (c) of study area. Source: (a) Map's link: http://d-maps.com/carte.php?num_car=4472\&lang=en (Retrieved 2013), (b) Report of Mie Prefecture, 2011. 
were illegally dumped into this site between 1995 and 1996. The dumped waste has approximately the area of $2800 \mathrm{~m}^{2}$ and the volume of about 30,000 to $40,000 \mathrm{~m}^{3}$ with the maximum depth of $14.7 \mathrm{~m}$ [28]. Groundwater around the site had been contaminated by the hazardous chemicals including chlorinated organic compounds and aromatics [28]. From 2002 to 2007, the countermeasures for treating the contaminated groundwater had been applied, construction of vertical slurry walls around dumped waste, soil capping, P\&T, and circulated water flashing on waste layers. As a result, the contaminated groundwater was treated to a great extent. Yet, 1,4-dioxane was detected in groundwater with high concentration after it was added into standards in late 2009.

The alternating sand and clay layers occur above the bedrock. The aquifer bed presents about $22 \mathrm{~m}$ below the ground surface. Based on the hydrogeological data, the aquifer beneath this illegal dumping site is separated into three aquifers by confining clay layers. The aquifer name was denoted from the top to the bottom as the first, second, and third aquifer respectively. The three aquifers have interaction in which groundwater flow directions of first and second aquifer mainly toward the north while that of third aquifer are in reverse direction. However, groundwater of the second and third aquifers were contaminated by 1,4-dioxane. Figure 1(b) shows contaminated area with concentration higher than standards which were obtained from the observed data in February, 2011.

Numerical simulation of groundwater at Kuwana illegal dumping site during condition without pumping was developed in a previous study by [27]. The geological model was developed using 14 geological cross-sections (see Figure 1(b)) provided by Mie Prefecture. Vertical slurry walls and underground tank were also considered. With model domain of $30,000 \mathrm{~m}^{2}$, the finite element mesh of $6 \mathrm{~m}$ and vertical division of 55 layers were con- sidered. Figure 2 shows the results of geological model with vertical exaggeration of 1.5 (see Figure 1(b) for locations of the viewing sections). Moreover, the previous model was calibrated so that hydraulic conductivity of each aquifer material, retardation factor, dispersion coefficients, boundary conditions, and other setting were determined.

\section{Roles of Numerical Simulation in Remediation Planning Based on VF-UP}

\subsection{What Is VF-UP}

VF-UP is a new approach developed by [19] for remedial planning for groundwater-contaminated sites, considering expected and/or unexpected uncertain events in the future to complete remediation effectively (see Figure 3). The expected uncertain events should be considered as much as possible during the remediation planning. On the other hand, unexpected uncertain events, VF-UP provides intermediate review processes during remediation and post review processes after completion of remediation. During the intermediate review, the remediation plans are flexible for adaption of any improvements if the remediation does not progress or not be completed as planned. In this case, remediation objectives and plans might be changed, e.g., additional or new remedial technologies will be applied after intermediate review process. Once the remediation is completed, and the site will be monitored to ensure whether the site is completely remedied. In the meant time, post review involved with local residents needs to be conducted for risk commutation. Actually, risk communication with residents is necessary from the early phase of revelation of the site, however it is very important to conduct risk communication after completion of remediation to restore the confidence of the residents and get their acceptance of remediation

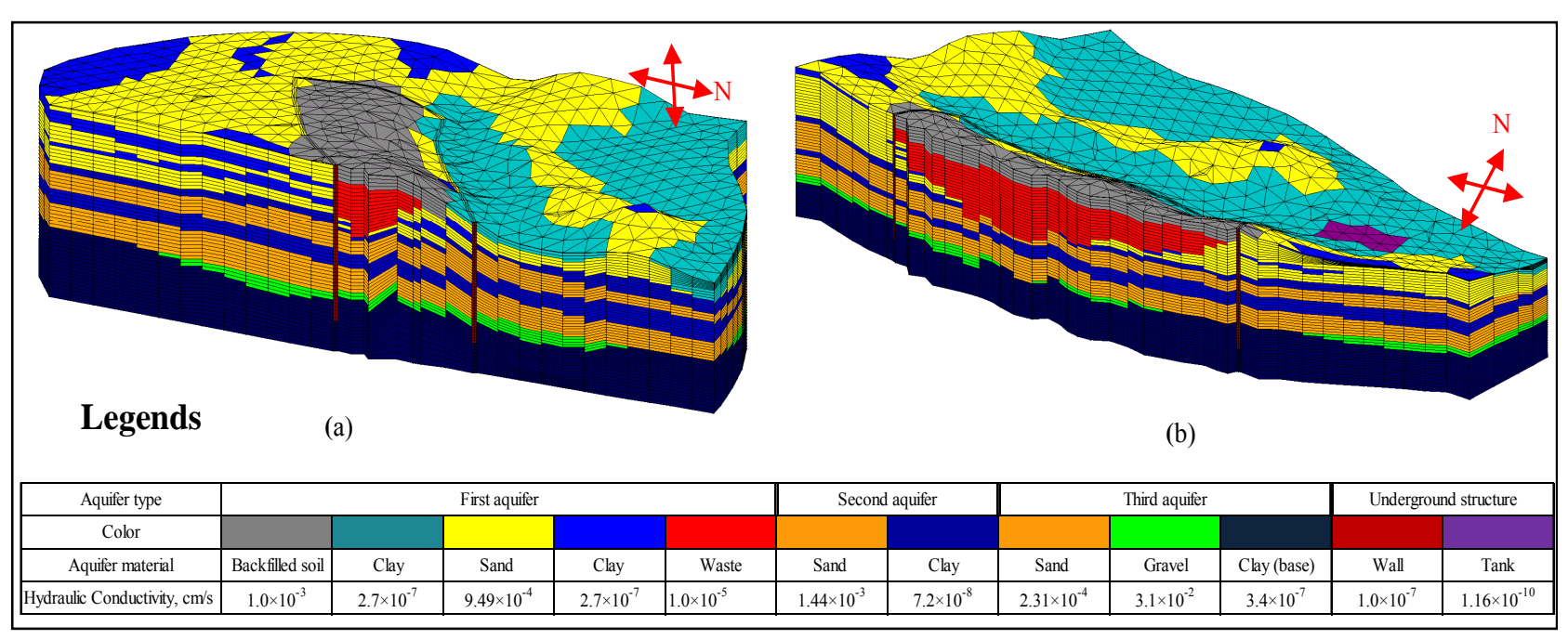

Figure 2. South-north (a) and west-east (b) geological cross-section. 
completion.

\subsection{Uncertain Factors in Remediation Planning}

The expected and unexpected events caused by many factors categorized as technical and social uncertain factors. Remediation planning based on VF-UP requires planners to consider expected uncertain events as much as possible. Once the uncertain events occur in the future, during remediation or after completion of remediation, they may exert a significant influence on the progress of the remediation. In Table 1, the first column shows the process of remedial planning from site discovering to the completion of remediation and followed by the technical and social uncertain factors [19].

The uncertain events may happen due to technical uncertain factors that might happen at each phase from the site investigation to the completion of remediation. Once the contaminated site is discovered, field investigation is carried out for data collection for analysis. Generally, the number of data is limited and discrete over space and time, therefore, the analysis of hydrogeological condition, waste distribution, and contaminant distribution contains much uncertainty. Next, remedial alternatives and plans were decided and implemented uncertainly. The selected technologies might not be good enough for specific site condition and contaminants to be treated. Moreover, design and implementation of technologies might not be proper because the predicted hydrogeological condition, waste and contaminant distribution also contain uncertainty. In addition, operation and maintenance might not be well progress as planned because uncertain events may occur. Lastly, the completion of remediation might be judged in different ways from person to person which required the adequate knowledge and experiences. Besides, enough information must be required to be properly judged the completion of remediation.

For the uncertain events caused by the social uncertain factors, may occur at any time of the whole processes for remediation planning. There is no good communication in society structure and not enough disclosure for residents about the site information. The registration or law could be revised any time in which a new compound might be added into environmental standards. Likewise, the remediation could be terminated due to the cuts in national subsidy. Furthermore, the new residents would complaint or protest against the contaminated site. Last but not least, sometimes the remediation is slower than available period of fund so that the remediation might be left incomplete.

\subsection{Objective of Numerical Simulation for Remediation Planning Based on VF-UP}

Considering the above technical uncertain factors, there might be many uncertain events will occur at Kuwana illegal dumping site during the remediation and after completion of remediation because the site has complex hydrogeological features. There are three aquifers with interaction and groundwater flows in different directions. Moreover, the site has a steep slope so that groundwater control for 1,4-dioxane containment is difficult. Since the

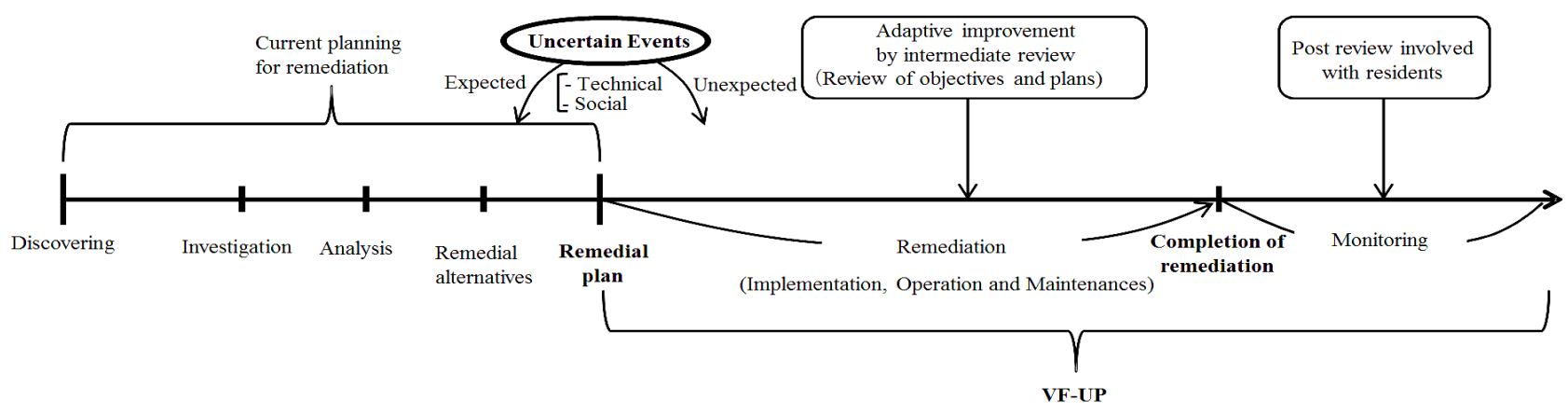

Figure 3. Remediation planning based on the concept of VF-UP.

Table 1. Uncertain factors considered in remediation planning based on VF-UP.

\begin{tabular}{|c|c|c|}
\hline Remediation planning phase & Technical uncertain factors & Social uncertain factors \\
\hline Investigation and analysis after site discovering & $\begin{array}{l}\text { Hydrogeological condition } \\
\text { Waste distribution } \\
\text { Contaminant distribution }\end{array}$ & $\begin{array}{l}\text { Society structure } \\
\text { Not enough disclosure } \\
\text { Registration or law }\end{array}$ \\
\hline Remedial alternatives, remedial plans and implementation & $\begin{array}{l}\text { Selected technologies } \\
\text { Design and implementation } \\
\text { Operation and maintenance }\end{array}$ & $\begin{array}{l}-\quad \text { new standard } \\
\text { - } \quad \text { subsidy cut } \\
\text { New residents }\end{array}$ \\
\hline Completion of remediation & How is "completion" judged? & Funding \\
\hline
\end{tabular}


number of data is limited and discrete over space and time, prediction of groundwater flow and 1,4-dioxane distribution might involve much uncertainty which exert the remediation to progress slowly or remediation could not be completed within time as planned. Due to the above conditions, the uncertain events might occur during remediation and after completion of remediation. Therefore, in this study, two uncertain events were considered for remediation planning for Kuwana site:

1) Decreasing of remediation efficiency in $P \& T$ for 1,4-dioxane-contaminated groundwater out of the vertical wall.

2) Emitting of 1,4-dioxane through the vertical walls because the remaining waste might contain 1,4-dioxane with high concentration.

Waste removal and P\&T were considered as remedial methods for 1,4-dioxane-contaminated groundwater at Kuwana illegal dumping site. The objective of numerical simulation for remediation planning based on the concept of VF-UP is to treat 1,4-dioxoane outside of the walls within 10 years and to prevent the spreading of 1,4-dioxane within the walls in case where a part of waste is remained. Numerical simulation will play an important role for estimating the effectiveness of waste removal and $\mathrm{P}$ $\& \mathrm{~T}$ plans by considering the above mentioned expected uncertain events. During remediation, the performance of remediation was reviewed if any additional measures are needed for improving the effectiveness of remediation. However, if a portion of waste is remained, future risks of 1,4-dioxane spreading through the walls into the surrounding environment might occur. The future risks might occur after completion of remediation. For that reason, numerical simulation can be used to predict the possible occurrence of future risks so that the measures against future risks can be considered beforehand.

\section{Model Development for Remediation}

\subsection{Governing Equations}

Basically, the development of any deterministic model for the groundwater flow and contaminant transport in groundwater flow system is a set of representative partial differential equations [29]. Equation (1) represents the net inflow into the volume that must be equal to the rate at which water is accumulating within the investigated volume [30],

$$
\frac{\partial}{\partial x_{i}}\left(k_{i j} \frac{\partial h}{\partial x_{j}}\right)=S_{s} \frac{\partial h}{\partial t}+Q
$$

where $i, j=1,2,3$ are principal coordinate directions; $k$ is the hydraulic conductivity $(\mathrm{m} / \mathrm{s}) ; h$ is the hydraulic head $(\mathrm{m}) ; S_{s}$ is the specific storage of porous me$\operatorname{dium}(1 / \mathrm{m}) ; Q$ is the local sources and sinks per unit- volume $(1 / \mathrm{s}) ; \quad x$ is the space coordinate $(\mathrm{m}) ; t$ denotes time (s).

The transport model can be represented by the following advection-dispersion equation [30]:

$$
\mathrm{R} \frac{\partial c}{\partial t}=-v_{i} \frac{\partial c}{\partial x_{i}}+\frac{\partial}{\partial x_{i}}\left(D_{i j} \frac{\partial c}{\partial x_{j}}\right)-Q_{s}
$$

where $R=1+\frac{(1-n) \rho_{s}}{n} K_{d}$ is retardation factor of solute (dimensionless), $\rho_{s}$ is density of dry matrix material $\left(\mathrm{kg} / \mathrm{m}^{3}\right), n$ is total porosity (dimensionless), $K_{d}$ is distribution coefficient $\left(\mathrm{m}^{3} / \mathrm{kg}\right) ; c$ is the concentration $(\mathrm{mg} / \mathrm{L}) ; \quad v$ is the Darcy velocity $(\mathrm{m} / \mathrm{s}) ; D$ is the dispersion coefficient $\left(\mathrm{m}^{2} / \mathrm{s}\right) ; Q_{s}$ is the concentration of solute of water that added from sources or sinks $(\mathrm{mg} / \mathrm{L} \cdot \mathrm{s})$.

\subsection{Solving Method and Used Software}

The application of finite element method to groundwater problem simulation was recently developed comparing to the finite difference method. For the finite difference model, the heads throughout the domain are defined only at the nodal points themselves while the finite element model permits the application of variational or weighted residual principles. Finite element method is flexible for irregular boundaries of problem and, moreover, in solving coupled problems, e.g., contaminant transport, or in solving moving boundary problems, such as moving water table [31].

For this model, numerical finite element methods based on the mixed Eulerian-Lagrangian approaches were used to solve the advection-dispersion equations. The Lagrangian methods are particularly suitable for solving advection term, while the Eulerian methods are more effective in dealing with dispersion term [32]. In this paper, a three-dimensional numerical model was developed by using GeoModeler software for simulating the groundwater flow and 1,4-dioxane transport. GeoModeler is a numerical finite element-based software for modeling subsurface flow, solute transport, and heat transport processes which was recently developed by a Japanese company, GMLabo Inc (http://www.gmlabo.co.jp/).

\subsection{New Model Development for P\&T Remediation}

\subsubsection{Groundwater Data for Pumping Condition}

Based on the data given by Mie Prefecture, groundwater had been normally pumped from the first and second aquifers for VOCs treatment. However, during two periods, groundwater from the third aquifer also pumped, from November, 2007 to March, 2008 and from December, 2009 to March, 2010. During these two periods, the 
maximum pumped water was found in February, 2010. The average pumping rate was about $52 \mathrm{~m}^{3} / \mathrm{d}$, in which $36 \mathrm{~m}^{3} / \mathrm{d}$ from the inside the walls (21 pumping wells) and $16 \mathrm{~m}^{3} / \mathrm{d}$ from the outside of the walls (six pumping wells), and much water was pumped from the second and third aquifers. Therefore, the groundwater data in February, 2010 will be used for the model calibration for pumping condition.

\subsubsection{Model Calibration}

It is never possible that one model can correspond to all the conditions on groundwater behavior [33]. For the case of Kuwana site, since the model domain is narrow, the pumping activities might influence the model boundary, e.g., the boundary might be lower than the condition without pumping. Therefore, the model calibrated using the data during the absence of pumping cannot be used to represent the groundwater behavior during pumping. For that reason, the existing model developed by [27] requires to be calibrated for pumping condition. The available measured groundwater head data in the first, second, and third aquifers were obtained from 12, 12, and 14 monitoring wells respectively. These data were used for comparing within the model result from each calibration. An error index, root mean square error (RMSE) calculated by comparing the calculated and observed heads was used to compare the goodness-of-fit of each calibration result. Firstly, the existing model was run for the pumping condition by inputting all the above pumping data, case 0 . As a result, the mean error of each aquifer ranged from -0.5 to $+0.5 \mathrm{~m}$ so that the decreasing boundary will be done for calibration limited to $0.5 \mathrm{~m}$. Normally, the boundary at the upstream (UB) is much influenced than that in the downstream (DB) of aquifer, therefore, the decreasing upstream boundary was prioritized for the calibration.

Table 2 shows that case 3 gave the better minimum RMSE value. In this case, only the upstream boundary of the third aquifer was decreased by $0.5 \mathrm{~m}$ while that of the first and second aquifers were kept the same as their original levels. The boundary of the third aquifer was influenced by the pumping because there was not enough water supplied from the boundary due to the low hydraulic conductivity and the aquifer thickness is relatively thin comparing the other two aquifers. For the first and second aquifers, plenty of water was supplied from the boundary, especially from the upstream boundary. Figure 4 shows the comparison between the calculated and observed head at monitoring wells in each aquifer. Additionally, groundwater flow directions in each aquifer from case 3 were found to be consistent with those obtained from the measured groundwater head data during pumping. And, if there is no such calibration, groundwater flow direction of the third aquifer would be in reversion directions with those from measured data during pumping.

\section{Remediation Planning Based on VF-UP}

\subsection{Estimation of Removed Waste and Pumping Rates for Remediation Plan}

The required time for contaminated groundwater reme-

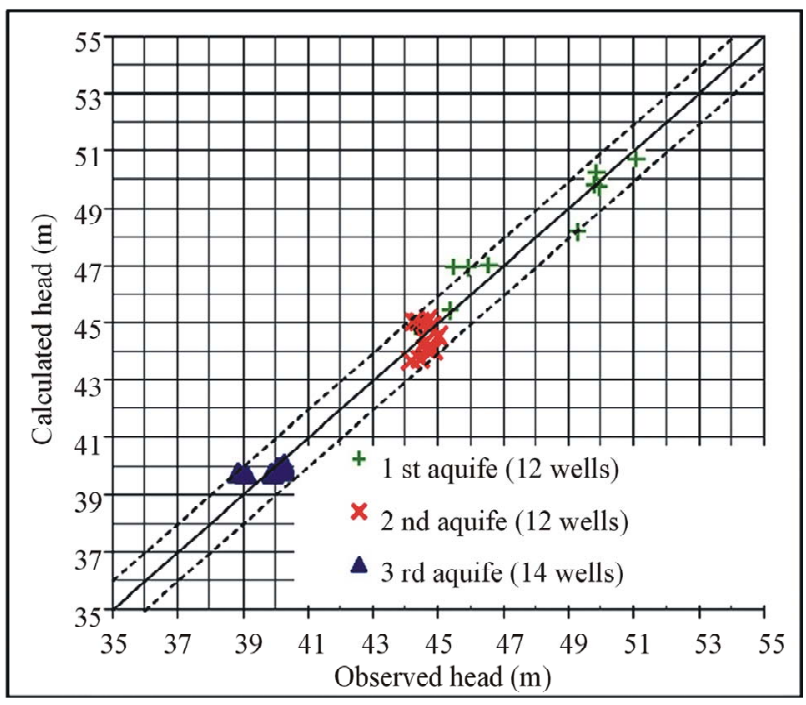

Figure 4. Comparison of calculated and observed groundwater head.

Table 2. Scenarios for model calibration and RMSE results.

\begin{tabular}{|c|c|c|c|c|c|c|c|c|c|c|c|c|c|c|}
\hline \multirow{2}{*}{ Calibration Case } & \multicolumn{2}{|c|}{ Case 0} & \multicolumn{2}{|c|}{ Case 1} & \multicolumn{2}{|c|}{ Case 2} & \multicolumn{2}{|c|}{ Case 3} & \multicolumn{2}{|c|}{ Case 4} & \multicolumn{2}{|c|}{ Case 5} & \multicolumn{2}{|c|}{ Case 6} \\
\hline & UB & DB & UB & DB & UB & DB & UB & DB & UB & DB & UB & DB & UB & DB \\
\hline First aquifer & $x$ & $x$ & $\checkmark$ & $x$ & $\times$ & $x$ & $x$ & $x$ & $\checkmark$ & $x$ & $\checkmark$ & $x$ & $\checkmark$ & $\checkmark$ \\
\hline Second aquifer & $\times$ & $\times$ & $\times$ & $x$ & $\checkmark$ & $\times$ & $x$ & $x$ & $\checkmark$ & $\times$ & $\checkmark$ & $\times$ & $\checkmark$ & $\checkmark$ \\
\hline Third aquifer & $x$ & $x$ & $x$ & $x$ & $\times$ & $x$ & $\checkmark$ & $x$ & $\times$ & $x$ & $\checkmark$ & $\times$ & $\checkmark$ & $\checkmark$ \\
\hline RMSE & \multicolumn{2}{|c|}{0.624} & \multicolumn{2}{|c|}{0.668} & \multicolumn{2}{|c|}{0.608} & \multicolumn{2}{|c|}{0.558} & \multicolumn{2}{|c|}{0.666} & \multicolumn{2}{|c|}{0.620} & \multicolumn{2}{|c|}{0.798} \\
\hline
\end{tabular}

$\times$ Groundwater head boundary was not changed.

$\checkmark$ Groundwater head boundary was decreased $0.5 \mathrm{~m}$ from the original level. 
diation will depend on several factors, which vary from site to site, e.g., it may take longer for the site where the contaminant source has not been completely removed [34]. Since the national subsidy is limited for Kuwana illegal dumping site, complete removal of waste from the site is impossible. This study has supposed four cases of waste removal with the same depth of about $15 \mathrm{~m}$ from ground surface, (a) no removal of waste, (b) one-third of waste is removed, (c) two-third of waste is removed, and (d) all of waste is removed. Based on the waste distribution and current 1,4-dioxane concentration distribution, the zone of waste to be removed is considered to start from eastern part of walls. For plan (c) and (d), extra wall which has similar property with the vertical slurry walls was added for the calculation (see Figure 1(b)). In order to determine pumping well locations and rates, plan (c) is considered because it is the most considerable case based on the waste distribution and 1,4-dioxane concentration distribution. In case where a portion of waste is remained, the remaining waste is considered as the continuous source of 1,4-dioxane with relative concentration of 1 unit. The 1,4-dioxane concentration distribution calculated in the previous model was used as initial condition, however, 1,4-dioxane within the removed waste was excluded in calculation.

According to 1,4-dioxane distribution in the previous study [27], locations of four pumping wells outside and two wells inside of walls were considered for plan (b). The wells inside of walls were used to pump groundwater from all aquifers, while the two wells outside the walls for only groundwater from the second and third aquifers. 1,4-Dioxane transport with 14 pumping plans were analyzed (see Table 3). The total pumping rates from each combination were limited by the capacity of treatment facilities of $60 \mathrm{~m}^{3} / \mathrm{d}$. As a result, the last pumping plan (P14) gives minimum average concentration outside of walls in each aquifer. Reviewing all the result from the 14 pumping plans, remediation is more effective when pumping rates of wells within waste layers increased, however, at least $10 \mathrm{~m}^{3} / \mathrm{d}$ of water should be pumped to treat 1,4-dioxane outside of the walls.

From this result, $50 \mathrm{~m}^{3} / \mathrm{d}$ is needed for pumping groundwater from the remaining waste for 1,4-dioxane containment and $10 \mathrm{~m}^{3} / \mathrm{d}$ is needed for pumping groundwater from outside of walls for 1,4-dioxane remediation. The estimated pumping plan was used then to calculate the effectiveness of remediation of other plans. Since the spatial distribution of waste is large, six and four pumping wells are required for plan (a) and (b) respectively. For plan (d), even all waste was removed, the remaining pumping capacity should focused on the treatment of 1,4-dioxane in groundwater of the third aquifer. Therefore, six pumping wells installed in only third aquifer. The average concentration observed at 19,29 and 30 monitoring wells outside of the walls of the first, second, and third aquifer respectively is used to evaluate the effectiveness of each plan. Corresponding to the each pumping plan, the results of remaining average concentration measured from those observation wells are shown in Figure 5. Groundwater outside of walls can be completely treated to lower than standard limit only by plan (d). For plan (a) and (b), there is no further ways to improve the efficiency of remediation because the 1,4-dioxane remained high in all aquifers. In contrast, in plan (c), groundwater of the first and second aquifers was completely treated, but the third aquifer is still contaminated. In addition, since the waste remained only in the first aquifer, the third aquifer will be easily remedied. For that reason, remediation in plan (c) suggested to review pumping plans if there is uncertain event that may exert the significant influence on remediation efficiency. During the review of pumping plans, two wells outside the wall found to be no longer effective and they were relocated into the zones where concentration was slowly decreased during remediation. Moreover, only groundwater from the third aquifer should be pumped. In addition, a new

Table 3. Scenarios of pumping plans and average 1,4-dioxane concentration result from wells outside of walls.

\begin{tabular}{|c|c|c|c|c|c|c|c|c|c|c|c|c|c|c|c|}
\hline \multicolumn{2}{|c|}{ Scenario of pumping plans } & $\mathrm{P} 1$ & $\mathrm{P} 2$ & $\mathrm{P} 3$ & P4 & P5 & P6 & P7 & P8 & P9 & $\mathrm{P} 10$ & P11 & $\mathrm{P} 12$ & $\mathrm{P} 13$ & $\mathrm{P} 14$ \\
\hline & \multirow{2}{*}{$\begin{array}{l}\text { Inside of walls } \\
\text { South of walls }\end{array}$} & \multicolumn{4}{|c|}{15} & \multicolumn{4}{|c|}{20} & \multicolumn{3}{|c|}{30} & \multicolumn{2}{|c|}{40} & 50 \\
\hline \multirow{4}{*}{$\begin{array}{l}\text { Pumping rate } \\
\left(\mathrm{m}^{3} / \mathrm{d}\right)\end{array}$} & & 5 & 10 & 15 & 20 & 5 & 10 & 15 & 20 & 5 & 10 & 15 & 5 & 10 & 5 \\
\hline & North of walls & 5 & 10 & 15 & 20 & 5 & 10 & 15 & 20 & 5 & 10 & 15 & 5 & 10 & 5 \\
\hline & Total & 25 & 35 & 45 & 55 & 30 & 40 & 50 & 60 & 40 & 50 & 60 & 50 & 60 & 60 \\
\hline & First aquifer & 0.037 & 0.036 & 0.034 & 0.033 & 0.035 & 0.032 & 0.031 & 0.030 & 0.031 & 0.030 & 0.029 & 0.029 & 0.029 & 0.029 \\
\hline \multirow{3}{*}{$\begin{array}{l}\text { Average } \\
\text { concentration } \\
\text { outside of } \\
\text { walls }\end{array}$} & Second aquifer & 0.048 & 0.044 & 0.043 & 0.041 & 0.045 & 0.041 & 0.040 & 0.038 & 0.040 & 0.038 & 0.038 & 0.038 & 0.037 & 0.036 \\
\hline & Third aquifer & 0.122 & 0.112 & 0.105 & 0.098 & 0.113 & 0.099 & 0.093 & 0.087 & 0.085 & 0.080 & 0.073 & 0.073 & 0.069 & 0.066 \\
\hline & All aquifers & 0.069 & 0.064 & 0.061 & 0.057 & 0.064 & 0.058 & 0.055 & 0.052 & 0.052 & 0.049 & 0.047 & 0.047 & 0.045 & 0.044 \\
\hline
\end{tabular}




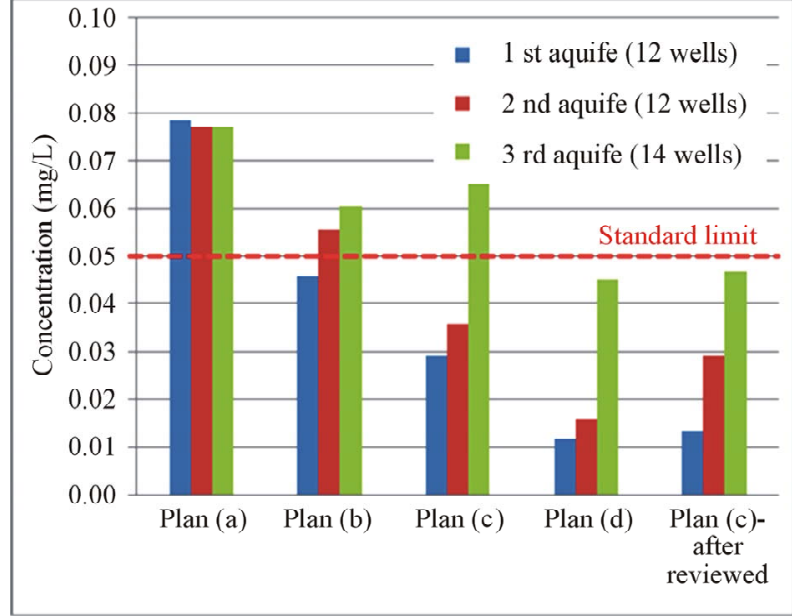

Figure 5. Average concentration of 1,4-dioxane in 10 years after remediation started.

well is required to the zone of removed waste because the concentration was remaining high.

After the plan (c) was completely revised, simulation was rerun for another 10 years using the 5 th year concentration of its result as initial concentration. As a result, Figure 6 shows that 1,4-dioxane concentration especially in the third aquifer was decreased drastically from the first year and gradually decreased to lower than standard limit in four to five years after the review of plan (c) (see Figure 6). Thus, in remediation planning, revised plan (c) and plan (d) could be proposed. However, if revised plan (c) is selected for the site, when P\&T will be shut down in future, risks of 1,4-dioxane spreading out of the walls might occur. Therefore, further study for future risks management should be conducted.

\subsection{Estimation of Pumping Rate for Future Risks Management after Completion of Remediation}

In order to predict the future risks that may occur after completion of remediation, we assumed that the remaining waste contains high 1,4-dioxane concentration. In this case, the whole remaining waste was assumed to contain 1,4-dioxane with relative concentration of 1 unit release constantly over calculation period for 15 years. As a result, if there is no pumping, 1,4-dioxane could spread out of the walls into the surrounding environment. For that reason, $\mathrm{P} \& \mathrm{~T}$ is required. Using two pumping wells as similar as in plan (c), in which groundwater was pumped from the waste layer of all aquifers with pumping rates varied from 0 to $60 \mathrm{~m}^{3} / \mathrm{d}$ in order to observe the trench of decreasing rate of concentration until the minimum spreading concentration is achieved.

To observe the spreading concentration, eight and nine observation points were placed from the south and north walls respectively until the model boundary. 1,4-dioxane spreading was simulated for 15 years with pumping. As a result, the average concentration of 1,4-dioxane from 17 observation points were plotted corresponding to the each pumping rate in Figure 7. In case of pumping rate reached $20 \mathrm{~m}^{3} / \mathrm{d}$ the average spreading concentration was minimized. Therefore, the required pumping rate for hydraulic containment to prevent future spreading of 1,4dioxane into surrounding environment was determined as $20 \mathrm{~m}^{3} / \mathrm{d}$.

\section{Conclusions}

With regardless of national subsidy, the removal of all

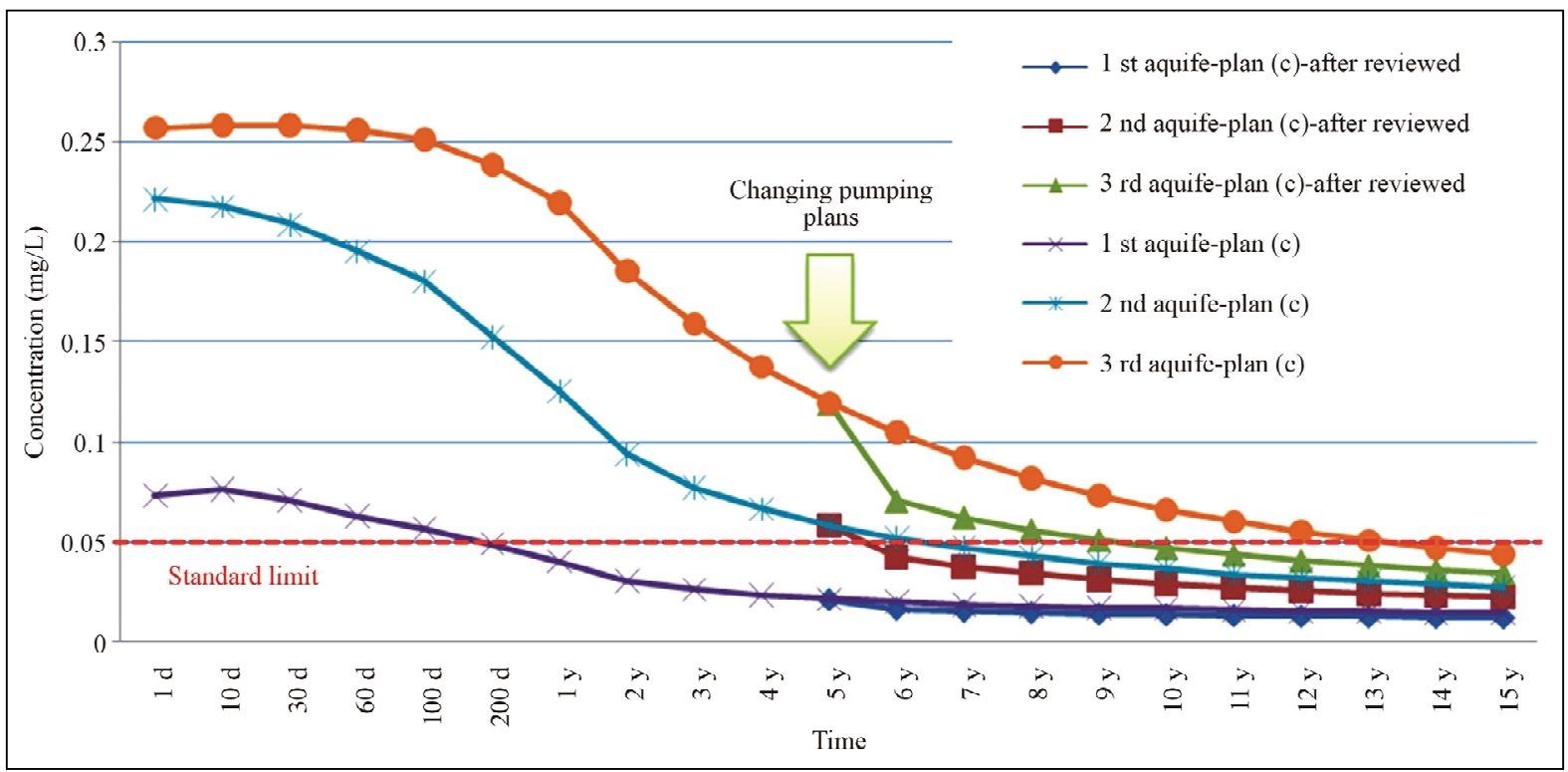

Figure 6. Decreasing average concentration in plan (c) from 1 day to 15 years. 


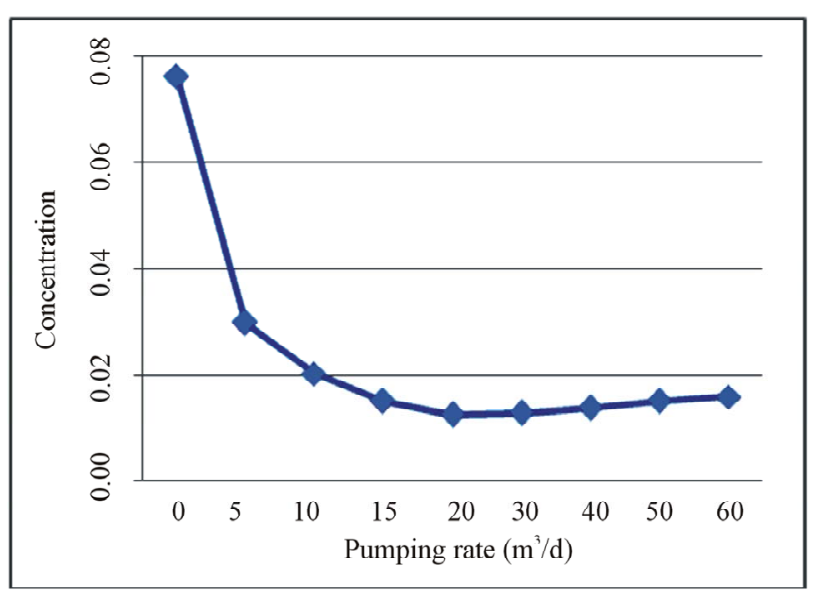

Figure 7. Average concentration of 1,4-dioxane outside of walls in $\mathbf{1 5}$ years simulation for each pumping rate.

the waste can be considered so that 1,4-dioxane-contaminated groundwater inside and outside of the walls at Kuwana site could be completely treated by P\&T within 10 years. However, since the national subsidy is limited, our study proposed a proper remediation plan to complete the remediation of 1,4-dioxane at Kuwana site in which at least two-third of waste should be removed and P\&T should be carried out simultaneously. For P\&T plan, two pumping wells are needed for pumping groundwater from the remaining waste with the total capacity of 50 $\mathrm{m}^{3} / \mathrm{d}$. Concurrently, for remediation of 1,4-dioxane outside of walls, four pumping wells were required with the total capacity of $10 \mathrm{~m}^{3} / \mathrm{d}$. However, to improve the effectiveness of remediation for the completion of remediation within 10 years, regarding the concept of VF-UP, pumping plan was changed at 5 years after remediation started. Furthermore, the future risks of spreading of 1,4-dioxane from the remaining waste throughout the walls into the surrounding environment was predicted by our numerical simulation by assuming that the remaining may contain 1,4-dioxane with high concentration. Therefore, the study suggested that groundwater within remaining waste must be pumped up at least $20 \mathrm{~m}^{3} / \mathrm{d}$ to keep containment of 1,4-dioxane within the remaining waste.

In conclusion, our numerical simulation was successfully applied to estimate the amount of waste to be removed and a proper pumping plan to achieve the objective of remediation planning for the real illegal dumping site based on the concept of VF-UP.

\section{Acknowledgements}

The authors sincerely thank Mie Prefecture for providing all the valuable data and documents for supporting this research. The authors also appreciate the financial supports for this research provided by Japan International Cooperation Agency (JICA) through its ASEAN Univer- sity Network/Southeast Asia Engineering Education Development Network (AUN/SEED-Net) project.

\section{REFERENCES}

[1] H. Yoshiro, "Industrial Pollution in Japan," United Nations University Press, 1992.

http://www.greenstone.org/greenstone $3 /$ nzdl? $\mathrm{a}=\mathrm{d} \& \mathrm{~d}=\mathrm{HA}$ SH149936ca3d8d74b977a251.5\&c=envl\&sib=1\&ed=1\& $\mathrm{p} . \mathrm{s}=$ ClassifierBrowse \&p.sa $=\& \mathrm{p} . \mathrm{a}=\mathrm{b} \& \mathrm{p} . \mathrm{c}=\mathrm{envl}$

[2] M. Fujikura, "Japan's Efforts against the Illegal Dumping of Industrial Waste," Environmental Policy and Governance, Vol. 21, No. 5, 2011, pp. 325-337. doi:10.1002/eet.581

[3] Y. Nakamura, "Waste Management and Recycling Business in the United States and Japan," 2007.

http://www.wcfia.harvard.edu/us-japan/research/pdf/07-0 9.Nakamura.pdf

[4] Ministry of Environment, "Establishing a Sound Material-Cycle Society,” 2010.

http://www.env.go.jp/en/recycle/smcs/a-rep/2010gs_full. pdf

[5] M. Shoya, Y. Tsukinaga, M. Aba and H. Yamamichi, "Basic Study on Characteristics of Molten Slag and Cement Produced with Illegal Dumped Industrial Wastes in Japan," Proceeding of 30th Conference on Our World in Concrete \& Structures, Singapore, 23-24 August 2005.

[6] Ministry of Environment, "Japan's Experience in Promotion of the 3Rs," 2005. http://www.env.go.jp/recycle/3r/en/approach/02.pdf

[7] M. A. B. Promentilla, T. Furuichi, K. Ishii and N. Tanikawa, "Evaluation of Remedial Countermeasures Using the Analytic Network Process," Waste Management, Vol. 26, No. 12, 2006, pp. 1410-1421. doi:10.1016/j.wasman.2005.11.020

[8] K. Kawamoto and K. Urashima, "Restoration and Recovery Technologies for Illegal Dumping of Waste Pollution," Science Technology Trends, Quarterly Review, No. 21, 2006, pp. 42-58.

[9] Ministry of Environment, "Environmental Quality Standards for Water Pollution," 2009. http://www.env.go.jp/press/press.php?serial=11846

[10] A. Yasuhara, "Chemical Components in Leachates from Hazardous Wastes Landfills in Japan," Toxicological \& Environmental Chemistry, Vol. 51, No. 1-4, 1995, pp. 113-120. doi: 10.1080/02772249509358229

[11] A. Yasuhara, H. Shiraishi, M. Nishikawa, T. Yamamoto, O. Nakasugi, O. T.kumura, K. Kenmotsu, H. Fukui, M. Nagase and M. Kawagoshi, "Organic Components in Leachates from Hazardous Waste Disposal Sites," Waste Management and Research, Vol. 17, 1999, pp. 186-197.

[12] A. Yasuhara, H. Shiraishi, M. Nishikawa, T. Yamamoto, T. Uehiro, O. Nakasugi, T. Okumura, K. Kenmotsu, H. Fukui, M. Nagase, Y. Ono, Y. Kawagoshi, K. Baba and Y. Noma, "Determination of Organic Components in Leachates from Hazardous Waste Disposal Sites in Japan by Gas Chromatography-Mass Spectrometry," Journal of Chromatography A, Vol. 774, No. 1-2, 1999, pp. 321-332. 


\section{doi:10.1016/S0021-9673(97)00078-2}

[13] World Health Organization, "Rolling Revision of the WHO Guidelines for Drinking-Water Quality: 1,4-Dioxane in Drinking-Water," 2004.

http://www.who.int/water_sanitation_health/dwq/chemica 1s/1,4dioxanesum.pdf

[14] W. H. Liu, M. A. Medina, W. Thomann, W. T. Piver and T. L. Jacobs, "Optimization of Intermittent Pumping Schedules for Aquifer Remediation Using a Genetic Algorithm," Journal of the American Water Resources Association, Vol. 36, No. 6, 2000, pp. 1335-1348. doi:10.1111/j.1752-1688.2000.tb05730.x

[15] T. K. G. Mohr, J. A. Stickney and W. H. Diguiseppi, "Environmental Investigation And Remediation: 1,4-Dioxane and Other Solvent Stabilizers" CRC Press, Boca Raton, 2010. doi:10.1201/EBK1566706629

[16] M. W. Priddle and R. E. Jackson, "Laboratory Column Measurement of VOCs Retardation Factors and Compare with Field Values," Ground Water, Vol. 29, No. 2, 1991, pp. 260-266. doi:10.1111/j.1745-6584.1991.tb00518.x

[17] R. J. Patterson, R. E. Jackson, B. W. Graham, D. Chaput and M. Priddle, "Remediation of Toxic Chemicals in a Contaminated Outwash Aquifer," Water Science Technology, Vol. 17, 1985, pp. 57-69.

[18] M. J. Zenker, R. C. Borden and M. A. Barlaz, "Occurrence and Treatment of 1,4-Dioxanein Aqueous Environments," Environmental Engineering Science, Vol. 20, No. 5, 2003, pp. 423-432. doi:10.1089/109287503768335913

[19] T. Furuichi, "Remediation of Environmental Contaminated Sites: New Approach for Practitioners," Ohmsha, Tokyo, 2013. (in Japanese)

[20] D.Becker, B. Minsker, R. Greenwald, Y. Zhang, K. Harre, K. Yager, C. M. Zheng and R. Peralta, "Reducing LongTerm Remedial Costs by Transport Modeling Optimization," Ground Water, Vol. 44, No. 6, 2006, pp. 864-875. doi:10.1111/i.1745-6584.2006.00242.x

[21] L. S. Matott, "Screening-Level Sensitivity Analysis for the Design of Pump-and-Treat Systems," Groundwater Monitoring \& Remediation, Vol. 32, No. 2, 2012, pp. 6680. doi:10.1111/j.1745-6592.2011.01375.x

[22] C. Zhen and P. P. Wang, "An Integrated Global and Local Optimization Approach for Remediation System Design," Water Resources Research, Vol. 35, No. 1, 1999, pp. 137-148. doi:10.1029/1998WR900032

[23] C. F. Harvey, R. Haggerty and S. M. Gorelick, "Aquifer Remediation: A Method for Estimating Mass Transfer Rate Coefficients and an Evaluation of Pulsed Pumping," Water Resources Research, Vol. 30, No. 7, 1994, pp. 1979-1991. doi:10.1029/94WR00763
[24] P. Bayer, M. Finkel and Georg Teutsch, "Cost-Optimization Contaminant Plume Management with a Combination of Pump-and-Treat and Physical Barrier Systems," Groundwater Monitoring \& Remediation, Vol. 25, No. 2, 2005, pp. 96-106. doi:10.1111/j.1745-6592.2005.0022.x

[25] D. M. Rizzo and D. E. Dougherty, "Design Optimization for Multiple Management Period Groundwater Remediation," Water Resources Research, Vol. 32, No. 8, 1996 , pp. 2549-2561. doi:10.1029/96WR01334

[26] C. Huang and A. S. Mayer, "Pumping-and-Treat Optimization Using Locations and Pumping Rates as Decision Variables," Water Resources Research, Vol. 33. No. 5, 1997, pp. 1001-1012. doi:10.1029/97WR00366

[27] R. Hem, T. Furuichi, K. Ishii and Y. C. Weng, “A New Approach for Prediction of 1,4-Dioxane Distribution in Groundwater at an Illegal Dumping Site in Japan," 2013. (under Review)

[28] K. Ishii, T. Furuichi and T. Imai, "A Study on Remedial Alternatives of Soil and Groundwater Contamination Caused by Improperly Controlled Landfill Sites-A Numerical Simulation Case Stud," Proceeding of Sardinia 01, Eighth International Waste Management and Landfill Symposium, Sardinia, 1-5 October 2001, Vol. 3, 2001, pp. 723-734.

[29] A. G. Bobba and S. R. Joshi, "Groundwater Transport of Radium-226 and Uranium from Port Granby Waste Management Site To Lake Ontario," Nuclear and Chemical Waste Management, Vol. 8, No. 3, 1988, pp. 199-209, doi:10.1016/0191-815X(88)90027-7

[30] K. Spitz and J. Moreno, "A Practical Guide to Groundwater and Solute Transport Modeling," John Wiley \& Sons, Inc, Toronto, 1996.

[31] H. F. Wang and M. P. Anderson, "Introduction to Groundwater Modeling: Finite Difference and Finite Element Methods," Academic Press, San Francisco, 1982.

[32] C. Zheng and G. D. Bennett, "Applied Contaminant Transport Modeling," John Wiley and Sons, Inc., New York, 2002.

[33] B. Barnett, L. R. Townley, V. Post, R. E. Evans, R. J. Hunt, L. Peeters, S. Richardson, A. D. Werner, A. Knapton and A. Boronkay, "Australian Groundwater Modeling Guidelines," Waterlines Report, National Water Commission, Canberra, 2012.

[34] US EPA, “A Citizen's Guide to Pump and Treat," EPA 542-F-12-017, 2012.

http://www.clu-in.org/download/citizens/a_citizens_guide to pump and treat.pdf 